


\section{Comunicação digital: uma questão de estratégia e de relacionamento com públicos}

Elizabeth Saad Corrêa

- Professora Titular do Departamento de Jornalismo e Editoração da Escola de Comunicações e Artes da Universidade de São Paulo (ECA-USP)

- Doutora em Ciências da Comunicação pela ECA-USP

- Mestre e graduada em Administração de Empresas, com ênfase em gestão tecnológica pela Faculdade de Economia e Administração da Universidade de São Paulo (FEA-USP)

- Responsável pelo conjunto de disciplinas na graduação e na pós-graduação do Departamento de Jornalismo e Editoração da ECA-USP que tratam da mídia e dos negócios digitais

- Coordenadora da área de Jornalismo junto ao programa de pós-graduação em Ciências da Comunicação da ECA-USP

- Coordenadora do Grupo de Pesquisas em Estratégia e Gestão de Mídias Digitais vinculado ao Programa de Pós-Graduação em Ciências da Comunicação (PPGCOM) da ECA-USP

- Estrategista web e consultora de empresas

- contato@bethsaad.com.br 
O artigo pretende discutir e delimitar o lugar da comunicação digital na estratégia de Comunicação Organizacional. Sugere ainda uma sistematização dos conceitos fundadores que norteiam as estratégias de Comunicação a partir do cenário das TICs e das mídias digitais. Por fim, apresenta o conceito de eficácia comunicacional e alguns exemplos de práxis brasileira, apontando rumos para a área.

PALAVRAS-CHAVE: COMUNICAÇÃO DIGITAL - COMUNICAÇÃO ORGANIZACIONAL • COMUNICAÇÃO ESTRATÉGICA INTEGRADA

\section{Abstract}

The article intends to discuss and delimit the role of digital communication in Organizational Communication strategies. It presents a systemization of the conceptual foundations that orientate the Communication strategies when we insert it in the scenario of ICTs and in that of the digital media. Finally, it presents the concept of effectiveness in communication and some examples of the Brazilian praxis, pointing directions for the area.

KEY WORDS: DIGITAL COMMUNICATION - ORGANIZATIONAL COMMUNICATION - INTEGRATED STRATEGIC COMMUNICATION

\section{Resumen}

El artículo pretende discutir y delimitar el papel de la comunicación digital en las estrategias de Comunicación Organizacional. Presenta una sistematización de los conceptos fundadores que orientan las estrategias de Comunicación cuando las insertamos en el escenario de las TICs y de los medios digitales. Finalmente, presenta el concepto de efectividad de comunicación y algunos ejemplos de la praxis brasileña, mientras que apunta las direcciones para el área.

PALABRAS CLAVE: COMUNICACIÓN DIGITAL - COMUNICACIÓN ORGANIZACIONAL - COMUNICACIÓN ESTRATÉGICA INTEGRADA 
O tema comunicação digital veio se popularizando no ambiente da Comunicação Empresarial com a mesma velocidade da absorção e uso das Tecnologias Digitais de Informação e Comunicação - as TICs. Um processo acelerado que, ao mesmo tempo, abriu todo um campo de inovações, criatividade e dinamismo e também toda uma sucessão de posicionamentos, usos e escolhas que acabaram por criar incompreensões, inadequações e entraves no desenvolvimento da rotina comunicacional nas empresas.

Optei por discutir neste artigo a necessidade e a oportunidade de sistematização das práticas de comunicação digital em ambientes organizacionais, seu vínculo estrito e indissolúvel com os processos desta comunicação e, especialmente, a importância estratégica da área digital vinculada a uma estratégia de Comunicação Integrada para qualquer tipo de organização. Quero deixar como mensagem que a chamada comunicação digital é, sim, estratégica, mas não tem sentido e validade se não fizer parte de um plano de Comunicação geral para a organização, este sim, o ponto vital para o sucesso da Comunicação nos ambientes empresariais.

Para sustentar tais propostas, além da necessária pesquisa bibliográfica, recorri a algumas fontes de observação empírica - diálogos e vivências com profissionais que atuam direta ou indiretamente em comunicação digital nas organizações - decorrentes da interação desta pesquisadora com os atores deste processo em anos recentes, seja em atividades de treinamento, seja em seus próprios ambientes de trabalho. Considero fundamental a inclusão da opinião de quem vivencia, na medida em que estamos tratando de um tema ao mesmo tempo novo em termos de existência consolidada e recente em termos da velocidade das mudanças que ocorrem neste cenário, fazendo com que a temática esteja em constante renovação.

Resumidamente, o objetivo maior desta contribuição é sistematizar os conceitos fundadores que norteiam as estratégias de Comunicação quando inserimos o cenário das TICs e das mídias digitais. Assim, este artigo deverá abordar o tema por meio da seguinte estrutura de conteúdo:

\section{Comunicação e tecnologia: um vínculo indissolúvel}

Ao longo da história de nosso processo de socialização, vimos o homem numa busca de formas, meios e modos de expressar suas necessidades e anseios e, mais do que tudo, numa busca de transmitir e dialogar sobre tais expressividades. O homem, não im- 


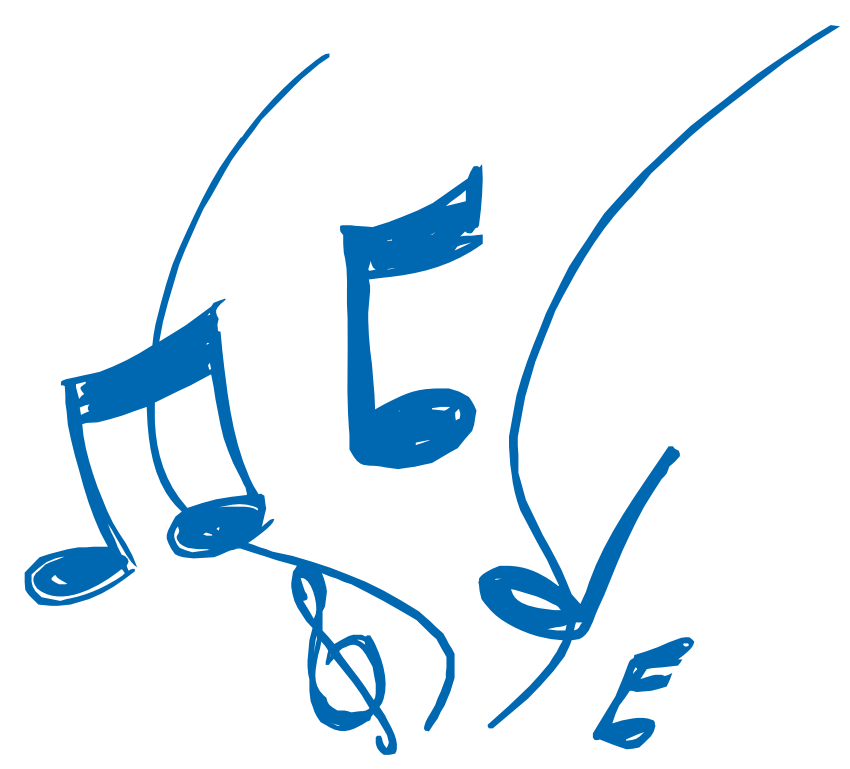

portando a época e os recursos, sempre foi o único produtor e controlador desse processo - a mediação e, da mesma forma, sempre foi o agente das grandes mudanças no processo de comunicação humana.

É fato que o processo de comunicação evoluiu na medida em que o homem encontrava sinergia entre modos, formas e meios de expressão. É fato que tal evolução vem sendo marcada pela introdução de novos modus faciendi e modus operandi que foram se sofisticando em patamares equivalentes à evolução do conhecimento e das tecnologias.

Portanto, destaco inicialmente a necessidade de compreendermos os conceitos fundadores do jargão do processo de inovação tecnológica em nossa sociedade: a ruptura e as aplicações transformadoras (as killer applications).

Estar envolvido no planejamento estratégico da Comunicação em qualquer grupamento social exige a compreensão de tais conceitos, pois, é a partir da vivência e experimentação deles decorrentes que os processos de Comunicação passam da eficiência para a eficácia.

Assim, o planejador da Comunicação contemporâneo, que vive a revolução digital, tem por missão a introjeção e a aplicação adequada dos conceitos de killer application, definido por Downes \& Mui (2000) como "todo novo bem ou serviço que estabelece toda uma nova categoria na economia e, que por ser pioneiro, domina o mercado e traz retornos significativos para o investimento inicial”, e de ruptura tecnológica, cuja definição agregada de diferentes autores refere-se a um cenário onde a introdução de uma killer application resulta na piora da performance do produto ou serviço impactado, pelo menos no médio prazo, e que tem a capacidade de criar novos valores e condições do mercado, inclusive pela adição de novos clientes, pois os produtos decorrentes da ruptura são mais baratos, mais simples, mais compactos e, quase sempre, mais convenientes ao uso. 
De forma direta, podemos dizer que hoje as TICs equivalem à killer application que produz serviços e produtos de comunicação específicos para a ambiência digital, com os quais o comunicador tem que criar, planejar e implementar estes novos serviços e produtos para que o seu trabalho alcance os resultados esperados.

Ocorre que, na prática, assistimos a um processo jamais visto de inovação/absorção de tecnologias para alavancar a comunicação humana que chega à beira do incontrolável. Um dos dilemas do comunicador contemporâneo é dar conta da compreensão deste processo, seu uso e sua obsolescência. Seria possível e necessário?

Para o campo da Comunicação (e para muitíssimos outros), têm-se tomado como parâmetros orientadores de tendências estudos macroeconômicos e estatísticos como a teoria das ondas de Kondratieff, as curvas de aprendizagem, a teoria de Bright e as análises de Christiansen, entre outros, que posicionam a internet como uma tecnologia de ruptura que veio para ficar por pelo menos 50 a 60 anos. Um detalhado estudo elaborado por Santos e Devezas (2003), pesquisadores da Universidade da Beira Interior, em Portugal, aponta que:

"a internet constitui-se em uma autêntica inovação de base, que está a transformar profundamente todo o sistema socioeconómico. Através da análise da sua evolução histórica podemos verificar que desde a sua génesis até agora, já foram cumpridos claramente os seis primeiros estágios da inovação de base segundo a classificação de Bright, podendo-se já notar fortes manifestações do $7^{\circ}$ estágio, isto é, o seu impacto economico-social. Ao longo da última década do século XX surgiram um grande número de novas empresas e um imenso número de novos empregos e novas actividades profissionais. Algumas das novas empresas geradas neste periodo adquiriram enorme dimensão financeira (Amazon, eBay, Yahoo! etc.), verificaram-se grandes fusões ( $A O L$ Time Warner, Compaq-HP etc.), e uma nova economia vem crescendo, atraindo para dentro dela outros sectores tradicionais da economia. Acima de tudo, cumprindo aquela caracteristica fundamental de todas as inovações de base, os hábitos das pessoas estão a transformar-se em função dela, inserindo-se profundamente no seu quotidiano.

A análise quantitativa da evolução permite-nos mostrar que o seu crescimento é logístico, com um tempo característico de cerca de 23 anos, valor este compativel com os apresentados por outras inovações de base que a precederam. Este crescimento atingirá até ao ano de 2004 a sua saturação quando então, o seu crescimento fisico completar-se-á, dando lugar a um novo ciclo da sua existência, o da consolidação final.

Verifica-se que todo o processo evolutivo da Internet está perfeitamente em fase com o desenvolvimento da última onda $\left(4^{a}\right)$ de Kondratieff. A sua Fase de Invenção correspondeu à fase ascendente e recessão primária desta onda, e a sua Fase da Inovação correspondeu à fase descendente. A sua Fase de Difusão já está iniciada e será a base do arranque para a próxima fase de expansão económica correspondendo ao início da $5^{a}$ onda de Kondratieff." 
Se considerarmos o uso das TICs ${ }^{1}$ como divisor de águas, fica evidente a aceleração dos ciclos tecnológicos da comunicação humana. Aceitando que uma das primeiras formas de expressividade do homem foram as pinturas rupestres do homem das cavernas (a ruptura inicial), vemos um longo processo de esforços do homem para ampliar, acelerar e encurtar os processos de disseminação de suas mensagens, com uma sucessão de rupturas: o uso da força motora animal e mecânica para disseminação de mensagens; a invenção da prensa e a formatação do livro, marcando a reprodução em série e a difusão do conhecimento; a introdução da eletricidade nos meios de comunicação desencadeando uma série de suportes e instrumentos como o telégrafo, o rádio, o telefone, o cinema, e a televisão entre outros; a ruptura da reprodução e armazenamento da imagem e do som com os gravadores de áudio, os videocassetes, chegando aos CDs e DVDs; a ruptura da massificação das mensagens com a aldeia global preconizada por Marshall McLuhan; até chegarmos aos últimos vinte anos, quando as transformações ocorridas superaram todas as rupturas anteriores.

Este dilema - a relação indissolúvel entre comunicação e tecnologia - coloca o comunicador contemporâneo num constante exercício de correlação entre a ciência das TICs e a arte de comunicar. Aqui, muito antes do pensamento comunicacional estratégico, temos que encontrar o equilíbrio entre constatações típicas da Ciência, a exemplo dos princípios, das recorrências fundantes, das explicações, das descobertas e das análises, e a característica criativa da arte de comunicar, numa rotina em que predominam as práticas, a experimentação de performances, a ação, a invenção, a síntese e a construção.

\section{O lugar da comunicação digital}

A Comunicação Empresarial contemporânea, não só pelos aspectos tecnológicos já apontados, mas fundamentalmente pela mudança social que as TICs aportaram para as ações de informar e comunicar, tem sido considerada como área estratégica em uma quantidade cada vez mais significativa de organizações ou agrupamentos sociais. Ao mesmo tempo e exatamente por sua instância, não se pode pensar esta comunicação sem uma visão de seu planejamento integrado e alinhado à estratégia global da organização. Na seqüência, se estratégica e integrada, a Comunicação contemporânea também atua direta e diferencialmente no processo de competitividade global em que as empresas hoje se vêem inseridas.

A exemplo do item anterior, são diversas as referências na literatura que sustentam esta visão. Optamos por apresentar alguns conceitos desenvolvidos por docentes e/ou pesquisadores nacionais, sem deixar, evidentemente, de considerar outros autores e

1 Aqui consideradas como o salto da base tecnológica analógica para a digital. 
referências internacionais que, pela delimitação de espaço para este artigo, não foram incluídos.

O professor Wilson Bueno (2000: 50), ao discorrer sobre o papel estratégico da Comunicação nas empresas, afirma que

"A Comunicação Empresarial evoluiu de seu estágio embrionário, em que se definia como mero acessório, para assumir, agora, uma função relevante na política negocial das empresas. Deixa, portanto, de ser atividade que se descarta ou se relega ao segundo plano, em momentos de crise e de carência de recursos, para se firmar como insumo estratégico, de que uma empresa ou entidade lança mão para idealizar clientes, sensibilizar multiplicadores de opinião ou interagir com a comunidade".

Em sua essência, a Comunicação Organizacional tem por função estabelecer os canais de comunicação e respectivas ferramentas para que a empresa fale da melhor maneira com seus diferentes públicos. Nesse sentido, todas as possibilidades de relacionamento com estes públicos devem estar integradas e alinhadas pela mesma visão estratégica, por um discurso uniforme e pela coerência das mensagens. Tal processo de integração estratégica envolve, segundo as proposições da professora Margarida Kunsch, um composto comunicacional que envolve a Comunicação Interna, a Comunicação Mercadológica (aquela vinculada diretamente aos produtos e serviços da organização) e a Comunicação Institucional (aquela que trata da imagem e da presença da organização em seus diferentes ambientes de atuação e influência). Para Kunsch (2003:90),

"As organizações têm de se valer de serviços integrados nessa área, pautando-se por políticas que privilegiem o estabelecimento de canais de comunicação com os públicos vinculados. A abertura de fontes e a transparência das ações serão fundamentais para que as organizações possam se relacionar com a sociedade e contribuir para a construção da cidadania na perspectiva da responsabilidade social".

Este é o cenário que abriga a chamada comunicação digital nas empresas. Ela ocorre estratégica e integradamente no composto comunicacional da organização. Portanto, considero que não podemos falar em Comunicação digital organizacional sem compreender e conhecer o plano estratégico de comunicação global. Assim, não cabe na proposição deste artigo restringir a comunicação digital à simples existência de um sítio na Internet ou a uma Comunicação Interna feita por meio do correio eletrônico. São visões inadequadas e reducionistas para uma proposta muito mais fundante.

Assim, apresento uma proposta de organização do conceito de comunicação digital coerente às proposições dos autores citados e, ao mesmo tempo, que seja clara e objetiva para sua aplicação por parte dos comunicadores. 
Conceituamos comunicação digital de per si como o uso das Tecnologias Digitais de Informação e Comunicação (TIC’s), e de todas as ferramentas delas decorrentes, para facilitar e dinamizar a construção de qualquer processo de Comunicação Integrada nas organizações. Falamos, portanto, da escolha daquelas opções tecnológicas, disponíveis no ambiente ou em desenvolvimento, cujo uso e aplicação é o mais adequado para uma empresa específica e respectivos públicos específicos.

Com isso, nem todo o processo comunicacional de uma organização é digital ou digitalizável, e nem toda TIC é adequada à proposta de Comunicação Integrada de uma dada organização. Temos, portanto, que definir e desenvolver no ambiente de Comunicação Organizacional o plano de comunicação digital integrada, baseado e sustentado pelo próprio plano de comunicação estratégica integrada.

Sistematizando, a comunicação digital integrada é construída a partir de uma avaliação de cada ação comunicacional prevista para as três grandes vertentes da Comunicação Integrada - Institucional, Interna e Mercadológica - e de seu cotejamento face ao público a que se dirige e ao nível de eficácia ampliado caso a ação seja executada por meio do uso das TICs.

\section{A Figura 1 apresenta esquematicamente nossa visão:}

\section{Comunicação DIGITAL integrada}

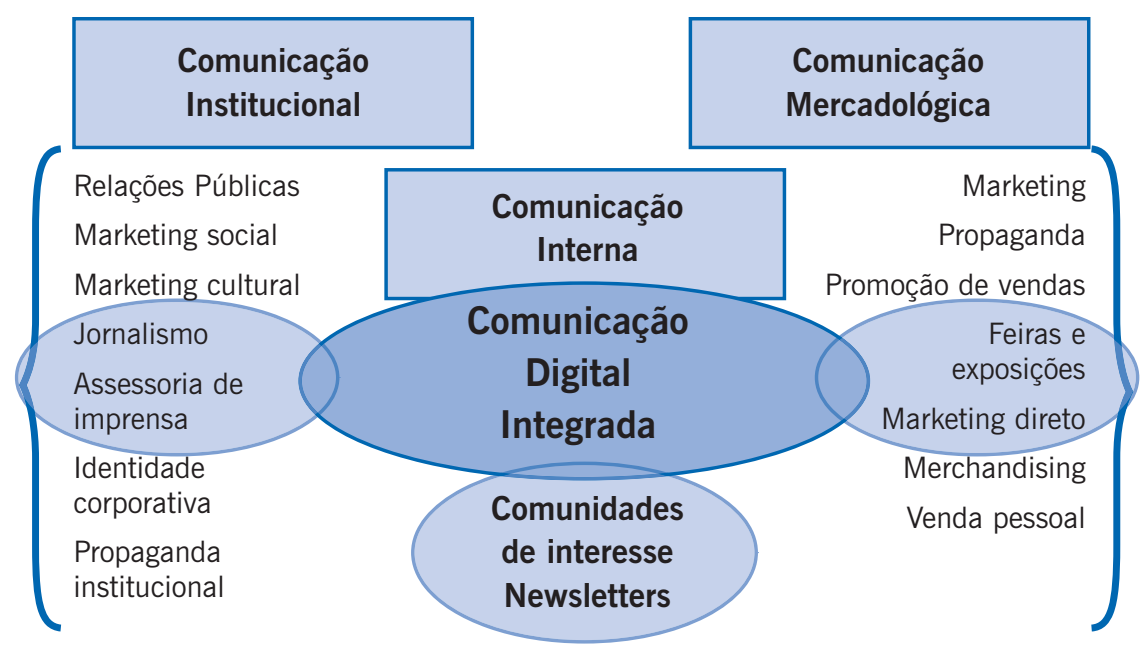

Fonte: Autora 
Um conceito correlacionado pode ser identificado no processo de comunicação digital integrada - a eficácia comunicacional. Integrar os recursos das TICs a partes e públicos específicos do plano de Comunicação Integrada de uma empresa exige que escolhas e decisões estejam baseadas no conceito de eficácia, não devendo o comunicador contentar-se apenas com a eficiência.

Maximiano (2003) desenvolve extensa reflexão sobre os termos. Resumimos a seguir suas principais idéias. A eficiência pode ser entendida como o esforço da empresa e seus colaboradores em fazer corretamente as atividades planejadas. Assim, tais esforços concentram-se nos meios e modos de execução, na resolução de problemas e na salvaguarda dos recursos disponíveis. Numa metáfora simplista, ser eficiente é seguir estritamente a receita de um bolo padrão para que ele seja consumido pelos comensais.

Já a eficácia traz em sua essência uma valoração e o uso de critérios para a execução das ações empresariais. Uma empresa ou uma ação são eficazes quando ocorre uma avaliação da forma mais adequada para sua execução, objetivando resultados e metas previamente acordados, dentro de uma proposta de otimização dos recursos disponíveis. Retomando a mesma metáfora, ser eficaz é fazer um ou mais bolos específicos para cada necessidade dos diferentes comensais que aguardam na boca do forno.

Transpondo estas idéias para o ambiente da Comunicação Empresarial integrada, podemos dizer que de maneira geral, toda e qualquer ação de comunicação é composta por dados e informações que podem ser recuperáveis a partir dos meios digitais. Numa visão de eficiência, este processo de recuperação e digitalização é suficiente. Mas, quando a área de Comunicação de uma organização começa a analisar, dentro do quadro geral de ações, quais poderão ser recuperadas, como e para quê recuperará-las num contexto de tecnologias digitais, iniciamos um movimento rumo à eficácia da comunicação digital. Por fim, aspectos como o tratamento comunicacional, visual e arquitetônico do material recuperado - aquilo que emerge nas telas de todos na empresa e nos clientes - serão determinantes para o sucesso da comunicação digital.

\section{Construção da estratégia de comunicação digital e seus sistemas de representação}

Alinhamento e integração à estratégia global de Comunicação, acrescidos das especificidades dos diferentes públicos diante dos meios digitais, exigem um processo detalhado de concepção e construção do composto de comunicação digital. É o que denominamos de estratégia de comunicação digital, um processo que se inicia pela compreensão de suas duas variáveis determinantes - estratégia e ambiente digital -, e por um delineamento claro do ambiente da empresa em seu espectro de atuação. 
Novamente, por conta das delimitações formais deste artigo, apresentamos a seguir um brevíssimo referencial destas variáveis determinantes.

Por que estratégia? Considerando que a comunicação digital é parte do plano de Comunicação Integrada da empresa, não seria mais simples o uso de termos como ações, tarefas ou até mesmo planos?

Iniciamos pelo conceito de estratégia. Definir o que é estratégia é uma tarefa que nem mesmo os mais conhecidos autores sobre o tema, como Stoner, Igor Ansoff, Peter Drucker, Henry Mintzberg, C.K. Prahalad e Michael Porter, os chamados gurus da administração das décadas de 80/90, chegaram a cumprir por inteiro, pois falamos de um processo de percepção empresarial totalmente vinculado ao ambiente, ao momento e às pessoas. Agregando as diferentes visões, vemos que ao trabalharmos com estratégia das organizações e discutirmos os seus processos de formulação e implementação, estamos tratando, ao mesmo tempo, de aspectos do ambiente interno e externo, da estrutura de funções e comunicação, do desenvolvimento e construção de produtos e/ ou serviços e de suas funções de distribuição e divulgação, bem como das relações com os clientes e também com outras entidades do ambiente.

Zaccarelli (2000) propõe sua visão de estratégia moderna, quando a empresa deixa de focar atenções apenas em análises e processos lógicos, muito característicos do planejamento estratégico, e passa a enfatizar a importância do jogo competitivo. No conceito de estratégia moderna, objetivos, planos, táticas e metas estão no plano de resposta à pergunta que deve pairar em todas as mentes de uma empresa: "Com quem disputamos o sucesso?” Para isso, a empresa deve estar em permanente estado de atenção para promover as mudanças certas, na hora certa.

Pontuando e sistematizando, consideramos que:

- estratégia envolve tomada de decisões acerca de produtos e tecnologia a serem desenvolvidos e/ ou absorvidos; da seleção do mercado e tipo de clientes a serem atingidos; e da criação e manutenção de vantagens competitivas;

- tal tomada de decisões pode ocorrer em nível genérico ou corporativo - a estratégia corporativa (corporate strategy), mas também em níveis específicos do negócio - a estratégia de negócios (business strategy);

- cabem no conceito e nas ações de configuração estratégica termos/atividades como: adequar o ambiente e a empresa; processos formais de análise; posicionamento de mercado; processo de aprendizado; trabalhar a cultura organizacional; desenvolver a visão de um líder; processo mental; reação ao ambiente; negociar e construir alianças, entre outras.

Com o avanço das TICs, evidenciado a partir do início dos anos 1990, praticamente todas as grandes empresas, e posteriormente também as médias e pequenas, engajaram- 
se nesse processo de transformação tecnológica paradigmática, no qual convulsionam-se os tradicionais papéis de emissor e receptor das mensagens. Com isso, as TICs assumem uma competência social, pois, sua performance deve encaixar-se nos padrões existentes das interações humanas para que ela seja significativa num sistema social específico. Tal competência, conforme análise apresentada por Corrêa (1994: 63),

"deve avaliar os valores culturais face aos conteúdos gerados pelas novas midias e, fechando o círculo, avaliar o impacto das mídias nos valores culturais [...] com isso, os determinantes das tecnologias de informação estão absolutamente relacionados às questões culturais, seus valores e seus recursos, diferenciando, ou melhor, ampliando o conceito do processo de inovação tecnológica, e da formulação de sua estratégia”.

No item 2 deste artigo exploramos o conceito de tecnologia de ruptura vinculado às TIC's e que deve ser aqui retomado para fecharmos o conceito de estratégia de comunicação digital. Christiansen (1997: XV) reafirma o conceito de ruptura e das conseqüentes mudanças empresariais para a sua absorção e alcance da competitividade. Para ele, a maioria das inovações tecnológicas é decorrente de melhorias no desempenho dos produtos - são as chamadas tecnologias de sustentação. Em geral, seus resultados reforçam a satisfação e as necessidades dos consumidores já conquistados e, principalmente, quase nunca provocam insucessos empresariais. Vez por outra, emergem no mercado tecnologias de ruptura que resultam na piora da performance do produto ou serviço, pelo menos no médio prazo, e defende que as tecnologias de ruptura têm a capacidade de criar novos valores e condições do mercado, inclusive pela adição de novos clientes, pois os produtos decorrentes da ruptura são mais baratos, mais simples, mais compactos e, quase sempre, mais convenientes ao uso.

Segundo o autor, a Internet é uma tecnologia classificada como de ruptura que, em curto prazo, piora a performance do produto ou serviço comunicacional ao qual a empresa está habituada, pois os indicadores de desempenho existentes não são adequados à inovação digital.

Um outro aspecto que pesa na construção de uma estratégia de comunicação digital é que empresas em geral convivem simultaneamente com a rotina baseada em tecnologias já dominadas e a cobrança do mercado em inovar por caminhos desconhecidos. Nesse ambiente, as decisões empresariais lógicas e competentes que são cruciais para o sucesso de curto e médio prazo, em geral levam a insucessos se aplicadas a inovações tecnológicas de ruptura. O dilema é como tomar decisões simultâneas e antagônicas sem encarar prejuízos e perdas?

Qualquer executivo de sucesso sabe que é preciso sair do dilema no mínimo intacto, e, na melhor das hipóteses, com o sucesso incondicional. Downes e Mui (1998: 58) afirmam que "a mudança nos princípios básicos da estratégia está no 'como' se desenvolvem produtos e se tornam operacionais. Para ter sucesso no mundo digital é preciso comer, dormir, respirar e pensar digitalmente". 
Um último aspecto fundamental e que, em geral, quando falamos de estratégias digitais ou posicionamentos das empresas com relação à Internet, acabamos por considerar como um dado, é o real significado da Internet para cada empresa. Martin (1996: 89) afirma que toda e qualquer estratégia de presença digital de uma empresa deve partir de um conceito claro do que é a Internet para o negócio. Sua proposta: "Internet não deve ser considerada apenas mais um meio de comunicação. Ela é o sistema de circulação da nova economia [...] a armadilha que geralmente vemos é confundir a tecnologia e o que ela possibilita através da internet com as necessidades do mercado. A internet é um meio para um fim e não um fim em si mesma. Reconhecer essa diferença é igual à compreensão da sociedade sobre o telefone, que se tornou uma aplicação fundamental por facilitar a comunicação e não porque era apenas uma inovação tecnológica".

Se temos, de um lado, a delicada operação empresarial que se desencadeia ao assumir as TICs como parte do processo de Comunicação Empresarial com seus diferentes públicos, temos, de outro lado, a compreensão exata das características digitais das mensagens. A mensagem difundida por meio das ferramentas da comunicação digital difere em sua essência daquelas verificadas nas formas de comunicação tradicionais.

Reforçando, o medium Internet requer mudanças nos processos editoriais e de linguagem para aproveitar as novas possibilidades de estruturação narrativa através do hipertexto, da multimídia e da interatividade. Para o professor espanhol Ramón Salaverría, o marco conceitual que sustenta a diferença de estruturas narrativas entre a comunicação tradicional e a comunicação digital está na retórica. Assim, segundo Salaverría (2005: 23), "o contexto retórico - aquele que resulta da combinação de circunstâncias específicas do emissor, do receptor, do canal, da linguagem e do conteúdo da mensagem-é diferente. [...] o jornalismo impresso (e da mesma forma o televisivo e o radiofônico) não é igual ao ciberjornalismo pela simples razão de que cada canal impõe um contexto retórico próprio."

O contexto retórico do ciberespaço ou das redes digitais transforma completamente os fatores referenciais de tempo e espaço. No dizer de Salaverría, tal contexto apresenta um policronismo - as múltiplas relações temporais que ocorrem entre a emissão e a recepção no ciberespaço - fazendo com que uma única elocução feita por um emissor possa ser recebida em coordenadas temporais completamente diferentes e por receptores distintos; e, uma multidirecionalidade - a troca de muitos para muitos, fazendo com que apenas no ciberespaço ocorram trocas comunicacionais personalizadas e interativas.

Assim, qualquer forma narrativa para o meio digital deve obrigatoriamente estar inserida no contexto retórico da policronia e da multidirecionalidade, sem que isto comprometa a compreensão e interpretação do sentido das mensagens por parte dos receptores, seja qual for a sua coordenada temporal e espacial. Além disso, de- 
ve incorporar as características-chave da comunicação nos meios digitais, a saber: a hipertextualidade - a capacidade de interconectar diversos textos digitais entre si; a multimedialidade - a capacidade, outorgada pelo suporte digital, de combinar na mesma mensagem pelo menos um dos seguintes elementos: texto, imagem e som; e a interatividade - a possibilidade do usuário interagir com a informação disponibilizada no meio digital.

Uma vez definidas as variáveis determinantes do processo de comunicação digital das empresas, é chegado o ponto essencial - a construção da comunicação propriamente dita - as mensagens mais adequadas para cada tipo de público, correlacionadas à ferramenta digital específica.

\section{A Figura 2 apresenta esquematicamente a estrutura que envolve a construção da estratégia de comunicação digital:}

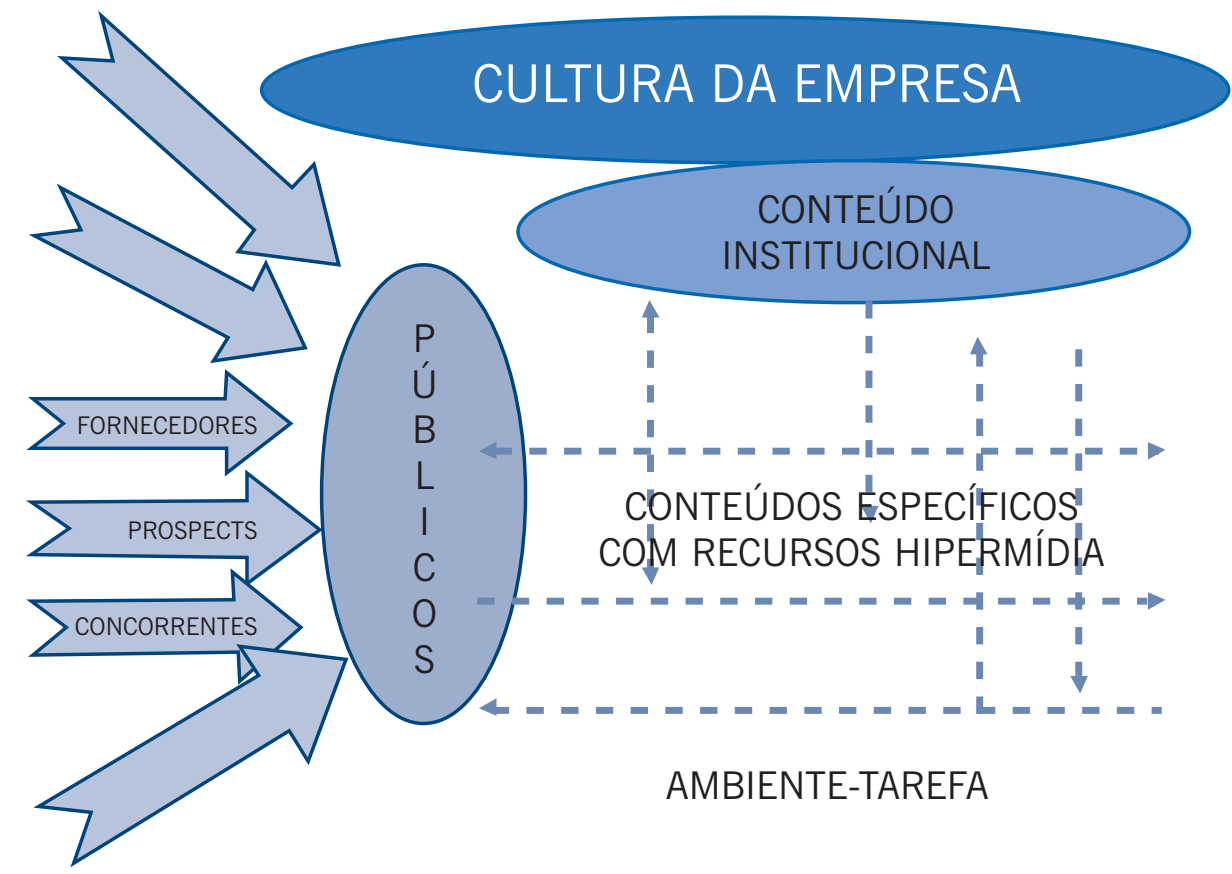

Fonte: Autora

O primeiro conjunto a ser considerado na formatação da comunicação digital de uma empresa é a sua cultura e a relação desta cultura com os quesitos de inovação, tecnologia, uso de computadores, de Internet, entre outros. Por exemplo, de nada adianta 
uma empresa lançar um portal de relacionamento digital com seus clientes se, internamente, em suas crenças e valores, usar computador não é fator determinante.

O segundo conjunto refere-se aos públicos estratégicos da empresa. Quem são e quais suas afinidades com o ambiente digital vivenciado. Por exemplo, se a empresa considera a comunidade de moradores do entorno de sua sede como um público estratégico, há que se verificar se este grupo tem por hábito o uso do computador e o acesso à Internet em sua rotina. Definir qual o suporte tecnológico para a criação de um canal direto de comunicação comunidade-empresa depende desta avaliação de uso. Um fale conosco disponível na página web da empresa só será eficaz se esta comunidade usa intensivamente a mídia digital. Caso contrário, provavelmente uma linha telefônica ou um balcão de atendimento presencial sejam mais eficazes.

É a partir da combinação cultura-características dos públicos que se inicia a estruturação do conteúdo das mensagens comunicacionais, formatadas quase que de forma personalizada. Inclui-se neste conteúdo o que chamamos de institucional, qual seja, o conjunto de informações sobre a empresa que devem ser transmitidas independentemente das características de cada público estratégico.

Chegamos, por fim, à última etapa de construção da estratégia de comunicação digital - a definição de seus sistemas de representação. Embora um sítio na web ou um portal corporativo sejam as formas mais evidentes e visíveis, existe uma multiplicidade de outros recursos de base digital que podem ser utilizados conforme a ação planejada, o conteúdo das mensagens, a característica do público e as respostas esperadas. É aqui que se percebe o exercício da arte de comunicar sem a perda da eficácia. Também é neste mesmo espectro que o comunicador corre o risco da ineficácia por conta da inadequação do recurso.

Atualmente os sistemas de representação mais comuns são: e-mail marketing, fóruns, interfaces gráficas - websites, intranets, portais corporativos, ferramentas de busca, transações, multimídia, mensagens instantâneas. E algumas das potenciais ineficácias decorrentes passam por situações como spam, excesso de informação, percepção de marca inadequada, usabilidade, design e layout não centrados no usuário, arquitetura complexa, conteúdo confuso, problemas técnicos no acesso ao site, entre outros. O detalhamento de cada um dos sistemas de representação e suas potenciais ineficácias extrapola os propósitos deste artigo.

\section{A busca da eficácia comunicacional e a práxis}

Apresentei até este ponto as principais idéias que considero fundantes para pensar a comunicação digital nos ambientes empresariais como uma ferramenta diferencial. 
Por outro lado, sabemos que a aceleração e a competitividade que pautam a rotina empresarial exigem respostas eficazes, em espaços de tempo muito curtos, podendo inviabilizar uma proposta de construção estratégica como a que apresentei.

Não se conquista eficácia comunicacional no ambiente digital de forma instantânea e a mesma pode ser atingida por meio de patamares que vão evoluindo conforme as necessidades do ambiente empresarial.

Numa compilação de informações coletadas junto a fontes primárias ${ }^{2}$ - profissionais que atuam direta ou indiretamente com comunicação digital e com diferentes posições das estruturas empresariais - pudemos notar que existem áreas sensíveis para a comunicação digital e que o mercado convive com uma sucessão de paradoxos.

Apenas para ilustrar essas opiniões, detectamos que, de maneira geral, existe uma visão positiva do uso da comunicação digital nas empresas, mas, ao mesmo tempo, dificuldades neste uso. Algumas das fontes apontam, por exemplo, que durante a elaboração do conteúdo de uma ação de comunicação digital ocorrem precipitações e ruídos na elaboração das mensagens e em seu processo de distribuição eletrônica. No caso de empresas globais, os entraves aparecem na diferença de culturas que não podem ser adequadas por conta de sistemas de representação fechados e uniformes mundo afora. Um outro ponto identificado refere-se à comunicação interna que, apesar de potencializada e valorizada com as intranets, acaba massificando o conteúdo das mensagens, num processo de redução de custos pela digitalização.

Pudemos notar, ainda, uma forte relação direta entre tamanho da empresa e intensidade de uso da comunicação digital sem o adequado processo de planejamento e implementação. Por fim, a convivência e a dificuldade de compatibilização e equilíbrio entre sistemas de representação digitais e analógicos ou tradicionais. São muitos os casos de supressão do jornal interno impresso e sua transposição integral em versão $P D F$ para as páginas da intranet, um dos mais graves erros contra a multimedialidade e as características do público leitor.

O cenário refletido reforça nossa proposição de que estamos vivenciando um processo longo, adaptativo e diretamente vinculado ao timing de cada empresa e respectivos ambientes.

No momento, alguns patamares de eficácia comunicacional digital podem ser sistematizados, todos balizados por três variáveis-chave: o grau de tratamento da informação no meio digital, o grau de visibilidade e diferenciação que se objetiva no ciberes-

2 O levantamento em questão foi realizado de forma não estruturada ao longo dos anos de 2004 e 2005, perfazendo em torno de 100 fontes entrevistadas ou contatadas. 
paço, e o grau de segmentação e personalização que se confere aos públicos estratégicos.

Desta forma, poderíamos identificar os seguintes patamares de busca da eficácia comunicacional:

- comunicação digital zero: refere-se a uma visibilidade genérica e unidirecional no ambiente digital, voltada para qualquer público sem identificação e oferecendo um conteúdo linear e estático, sem qualquer possibilidade de aprofundamento ou correlação;

- eficiência comunicacional: refere-se ainda a uma visibilidade genérica com um maior cuidado no tratamento do conteúdo das mensagens. A empresa define um sistema computacional de gestão das informações, possibilitando a organização hierárquica dos dados para produzir correlações e conseqüentes significados, sua representação semântica associada à subjetividade e significação junto aos públicos, e a inclusão de maiores cuidados com os aspectos de identidade visual, arquitetura e design, aumentando as possibilidades de percepção por parte dos públicos. Neste patamar ainda não se definem com clareza as diferenças entre os públicos estratégicos;

- eficiência comunicacional em transição: aqui já podemos identificar diferentes públicos estratégicos e o uso paulatino de sistemas de representação bidirecionais, que permitem o diálogo e a interação. Existem planos específicos de geração e troca de mensagens de formas diferenciadas para cada ação e uma definição da identidade visual e da arquitetura da informação que apóia esta construção de relacionamentos com os públicos.

Optamos por não configurar o último patamar - a própria eficácia comunicacional - uma vez que estamos em plena transição. Encerramos esta contribuição com algumas considerações que favorecem o atingimento da eficácia. Ela ocorrerá quando: as informações digitalizadas - mensagens, conteúdos - passam pelo crivo de pessoas, entrando no mundo real; conseguem produzir conhecimento no público focado; produz aplicações pragmáticas e conectadas com o mundo real; ocorre a interação do usuário com a interface como parte da experiência; gera competências e capacidade de aplicação do conhecimento em diferentes situações do mundo real.

Portanto, e finalizando: quanto mais integrada a proposta de comunicação com os diferentes públicos no meio digital, mais complexo o sistema de representação; quanto maior a complexidade, maiores as possibilidades de ações de relacionamento eficazes com os públicos. 


\section{Bibliografia}

BUENO, Wilson da Costa. A Comunicação como espelho das culturas empresariais. Revista Imes - Comunicação, ano I, n 1 , jul/dez 2000.

CHRISTIANSEN, Clayton M. The innovators dilemma: when new technologies cause great firms to fail. Boston: Harvard Business School Press, 1997.

CORRÊA, Elizabeth Saad. Tecnologia, Jornalismo e competitividade: o caso da Agência Estado. Tese de doutoramento apresentada junto ao Departamento de Jornalismo e Editoração da ECA-USP. São Paulo: ECA-USP, 1994. Documento mimeografado.

DOWNES, Larry e MUI, Chunka. Unleashing the killer App: digital strategies for market dominance. Boston: Harvard Business School Press, 1998.

KUNSCH, Margarida Maria Krohling. Planejamento de Relações Públicas na Comunicação Integrada. 4a. Ed. São Paulo: Summus, 2003.

MARTIN, Chuck. The Digital Estate: strategies for competing, surviving and thriving in an internetworked world. New York: McGraw Hill: 1996.

MAXIMIANO, Antonio Cesar Amarú. Introdução à Administração. São Paulo: Atlas, 2003.

SANTOS, Humberto e DEVEZAS, Tassaleno Campos. Análise e interpretação do crescimento da internet. Disponível em http://www.dem.ubi.pt/ humberto/Investiga/html/sintese-8.htm, e acessado em 31 de janeiro de 2006.

ZACCARELLI, Sergio B. Estratégia e sucesso nas empresas. São Paulo: Saraiva, 2000.

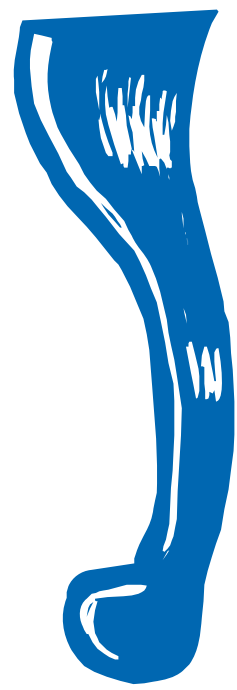

ANO $2 \cdot$ NÚMERO $3 \cdot 2^{\circ}$ SEMESTRE DE $2005 \cdot$ organicom • 111 